\title{
25 Research Square \\ Incidence And Predictors of Relapse After Stopping Antiviral Therapy In Pediatric Chronic Hepatitis B
}

Piyush Upadhyay

Institute of Liver and Biliary Sciences

\section{Bikrant Bihari Lal}

Institute of Liver and Biliary Sciences

Vikrant Sood

Institute of Liver and Biliary Sciences

\section{Rajeev Khanna}

Institute of Liver and Biliary Sciences

Ekta Gupta

Institute of Liver and Biliary Sciences

Archana Rastogi

Institute of Liver and Biliary Sciences

Seema Alam ( $\square$ seema_alam@hotmail.com )

Institute of Liver and Biliary Sciences https://orcid.org/0000-0003-0888-8625

\section{Research Article}

Keywords: ccc-DNA, biochemical relapse, virological relapse, HBeAg, pediatric hepatitis B, pegylated interferon, stopping rule, repeat liver biopsy, antiviral therapy

Posted Date: December 28th, 2021

DOI: https://doi.org/10.21203/rs.3.rs-1150647/v1

License: (c) (i) This work is licensed under a Creative Commons Attribution 4.0 International License.

Read Full License 


\section{Abstract}

Objective: The objective was to evaluate the incidence of relapse after stopping antiviral therapy and to identify the predictors of relapse.

Methods: All HBsAg positive children with who had been on antivirals for at least 2 years with undetectable HBV-DNA and normal alanine-aminotransferase (ALT) on three consecutive occasions over last 12 months were included. Antivirals were stopped if liver biopsy showed histological activity index $<5$ and fibrosis (metavir) $<3$. Children were monitored for virological relapse (elevation of HBV-DNA $>2000 \mathrm{IU} / \mathrm{mL}$ ) and biochemical relapse (ALT levels $>2 \times$ upper limit of normal (ULN)). Those having biochemical relapse were started on pegylated interferon alpha-2b based sequential therapy.

Results: Antivirals were stopped in $31 \mathrm{HBsAg}$ positive children. Virological and biochemical relapse was seen in $12(38.7 \%)$ and 5 (16.1\%) children within 12 months of stopping antiviral treatment. Majority of virological relapse occurred within a month and biochemical relapses within 6 months of stopping therapy. HBeAg positive status at the time of stopping antiviral therapy (HR: 7.206, $p=0.005$ ) and longer time taken for HBV-DNA to become undetectable while on antivirals (HR: 1.030, $p=0.037$ ) were found to be the 2 independent predictors of relapse after stopping antiviral treatment.

Conclusion: Discontinuation of antiviral treatment in children with $\mathrm{CHB}$ resulted in relapse in one third of the patients. Relapse was more common in those with $\mathrm{HBeAg}$ positivity at the time of stopping therapy and in those with longer time taken for HBV-DNA to become undetectable on antivirals.

\section{Introduction:}

The goal of antiviral therapy in chronic hepatitis $\mathrm{B}(\mathrm{CHB})$ patients is to improve survival by preventing the progression of liver damage to cirrhosis, end-stage liver disease, hepatocellular carcinoma (HCC) and death [1-2]. There are clear guidelines for stopping antiviral therapy in adults [3-6]. However, there is no study to evaluate the natural course and risk of relapse after stopping therapy in children with chronic hepatitis $B$. There is no ambiguity in stopping antiviral therapy in children who achieve hepatitis $B$ surface antigen (HBsAg) seroclearance. However, only 1.7 to $8.3 \%$ of children treated with antivirals achieve HBsAg seroclearance [7-10]. There is no consensus about the duration of antiviral therapy in the vast majority who continue to remain HBsAg reactive. Initiation of antivirals at a very young age in children coupled with lack of definite endpoint for stopping therapy implies extremely long cumulative duration of exposure to antivirals, thereby increasing the risk of adverse events and drug resistance [7-10]. The incidence and predictors of relapse after stopping antiviral treatment in children with $\mathrm{CHB}$ has never been studied previously. Therefore, we planned this pilot research to determine the incidence and identify risk factors of relapse on stopping antiviral therapy in children with CHB.

\section{Methods:}


It was a prospective interventional study conducted at a tertiary care centre over a period of 2 years (January 2019 to December 2020). Approval was obtained from the institutional ethical committee vide letter no IEC/2019/67/MA-06. The study was conducted in accordance with the ethical standards of the institutional and national research committee and with the 1964 Helsinki Declaration and its later amendments. Children between the ages of 2 and 18 years with $\mathrm{CHB}$ who had received antivirals for at least 24 months with (i) alanine aminotransferase (ALT) levels persistently < 1.5 times the upper limit of normal (ULN) (3 consecutive readings done 6 months apart in last 12 months); (ii) hepatitis B virus deoxyribonucleic acid (HBV DNA) not detected on 3 consecutive occasions 6 months apart in last 12 months and (iii) whose parents/ guardians gave consent for the study, were included. Normal ALT levels were defined as per the cut-offs obtained from SAFETY study [11]. Children with family history of cirrhosis, HCC or co-infection with hepatitis $\mathrm{C}$ virus and human immuno-deficiency virus were excluded. Liver Biopsy was done to evaluate the histological activity index (HAI) and fibrosis as per Ishak staging [12]. Children with $\mathrm{HAl}<5$ and fibrosis $<3$ in liver histology were offered the option of stopping antiviral therapy. Additionally, quantitative estimation of covalently closed circular DNA (ccc-DNA) was also done in the liver tissue. ccc-DNA levels were measured by real-time polymerase chain reaction (PCR) based inhouse assay on lightcycler 480 (LC480) (Roche Diagnostics, Netherlands) instrument using following primers: Forward primer: 5'-CTCCCCGTCTGTGCCTTCT-3'; Reverse Primer: 5'-GCCCCAAAGCCACCCAAG-3'. This is a qualitative real-time PCR based assay using sybergreen probes for the target detection [13]. HBV-DNA was measured in the plasma samples by using automated real-time PCR kit, COBAS ${ }^{B}$ AmpliPrep/COBAS® TaqMan®, v2.0 (Roche Diagnostics, GmbH, Mannheim, Germany). This is an automated hepatitis B viral load quantitative assay needing $650 \mu \mathrm{L}$ of serum or plasma, with the linear range of quantification being 1.3-8.23 $\log _{10} \mathrm{IU} / \mathrm{ml}$ in all of them. HBsAg quantification was done by chemiluminiscent immunoassay (CLIA) method (Abbott Laboratories, Chicago, IL, USA) [14].

After stopping the antivirals, the patient was followed up at 1 month, 3 months and every 3 months thereafter. Workup at each follow up included: ALT, quantitative HBV-DNA (qHBV-DNA), quantitative HBsAg (qHBsAg), HBeAg, alfa-fetoprotein (AFP) and ultrasonography of the abdomen. Virological relapse was defined as any elevation of qHBV-DNA > $2000 \mathrm{IU} / \mathrm{mL}$. Biochemical relapse was defined as elevation of ALT > 2 times ULN. Primary outcome of the study was the incidence of relapse after stopping antiviral therapy. Secondary outcome was identification of the predictors of relapse after stopping antiviral therapy. The predictors studied included clinical parameters, type of therapy, HBeAg seroconversion status, time taken for HBV-DNA to become undetected on therapy, HBV genotype, ccc-DNA levels, duration of normal ALT before stopping therapy and qHBsAg at the time of stopping antivirals. Those with only VR were continued on regular follow up whereas those with VR as well as BR were treated with combination therapy: 8 weeks of antivirals (entecavir in those younger than 12 years; tenofovir in those older than 12 years), followed by combination of peg-IFN alpha $2 b\left(60 \mathrm{mcg} / \mathrm{m}^{2} /\right.$ week) for 48 weeks. The study design is depicted in figure 1.

Statistical analysis: All analyses were performed with SPSS 22.0 (SPSS, Chicago, IL). As this was a pilot study, all the children fulfilling the inclusion criteria during the study period were enrolled. Continuous 
variables were expressed as median and inter-quartile range (IQR), while categorical variables were expressed as proportions. Both categorical and continuous variables were analyzed using cox regression analysis. Cox regression model was used for univariate and multivariate analyses for predictors of relapse. Receiver operating characteristic curves were used to calculate the area under the receiver operating characteristic curve (AUROC).

\section{Results:}

A total of $114 \mathrm{CHB}$ children were screened during the study period, out of which 39 (34.2\%) children satisfied the criteria for inclusion in the study. Eight of them were HBsAg negative; whose treatment was stopped without a repeat liver biopsy. Parents of all remaining $31 \mathrm{HBsAg}$ reactive children gave consent for inclusion in the study, liver biopsy and consideration of stopping antiviral treatment. All the 31 children had $\mathrm{HAl}<5$ and fibrosis $<3$ in liver biopsy and all their parents agreed to stop antiviral treatment with close follow-up. Table 1 depicts the baseline clinical, biochemical and virological characteristics of these children at the time of enrolment in the study. The cohort predominantly consisted of children with genotype D (75\%). All of these children had been HBeAg reactive chronic hepatitis B at the time of initiation of their antiviral therapy. Majority were males (96.8\%) with median age of 15 years (IQR: 11.5-17 years). Thirteen (41.9\%) were persistent HBeAg reactive (no HBe seroconversion) at the time of enrolment. The median ccc-DNA in the liver histology was $4 \log _{10}$ copies/ml (IQR: $3.1 \log _{10}-5.4 \log _{10}$ ). None had advanced fibrosis either on histology or on transient elastography (TE) (median TE: $5 \mathrm{kPa}$ (4.4 - 5.4)). These children had received oral antivirals for a median duration of 60 months (IQR: 36-78 months). They had a normal ALT on therapy for a median on 30 months.

Relapse after stopping antivirals: All $31 \mathrm{HBsAg}$ positive children enrolled in the study were followed up for a minimum of 12 months. Twelve of these 31 children (38.7\%) developed virological relapse. Five children (16.1\%) additionally had a biochemical relapse. Most $(58.3 \%)$ of the virological relapse occurred within a month of antiviral stoppage (figure 2). Biochemical relapse was more common in those developing virological relapse at 3 months or beyond after stopping antivirals. In 4 children, virological as well as biochemical relapse were detected at the same time-point during follow up (Figure 2). Of the 7 children who developed only virological relapse, 6 (85.7\%) developed it within $1^{\text {st }}$ month after stopping antiviral treatment. None of the 8 children with HBsAg negative status showed virological or biochemical relapse till 12 months of follow up.

Risk factors for development of relapse: On univariate analysis, $\mathrm{HBeAg}$ positive status at the time of stopping therapy (OR: $7.058,95 \% \mathrm{Cl}: 1.825-27.29, \mathrm{p}=0.005)$ and longer time taken for qHBV-DNA to become undetectable on antiviral treatment (OR: $1.024,95 \% \mathrm{Cl}: 1.003-1.046, \mathrm{p}=0.028)$ were the significant predictors of virological relapse after stopping antiviral therapy (Table 2). All the variables with $p$ value less than 0.1 on univariate analysis [(i) HBeAg positive at the time of stopping therapy; (ii) time taken for qHBV-DNA to become undetectable; and (iii) duration of normal ALT on antivirals] were entered in the Cox regression model. On Cox regression analysis, HBeAg positive status at the time of stopping therapy (HR: $7.206,95 \% \mathrm{Cl}: 1.81-28.74, \mathrm{p}=0.005$ ) and time taken for qHBV-DNA to become undetectable 
(HR: $1.030,95 \% \mathrm{Cl}: 1.002-1.058, \mathrm{p}=0.037)$ were independent predictors of relapse (Table 2). This model predicted occurrence of relapse with an AUROC of 0.855. A longer time taken (more than 22.5 months) for qHBV-DNA to become undetectable predicted virological relapse with a sensitivity of $83.3 \%$ and specificity of $47.4 \%$ (AUROC: $0.737,95 \% \mathrm{Cl} 0.56-0.913, \mathrm{p}=0.029$ ) (Figure 3). Children who were HBeAg positive at the time of stopping therapy were at significantly higher risk of relapse as compared to those who were HBeAg negative (log rank 10.705, $\mathrm{p}=0.001$ ) (Figure 4). In the present study, $69.2 \% \mathrm{HBeAg}$ positive children relapsed within 12 months as against $16.7 \%$ of the HBeAg negative children (OR: 7.058, $95 \% \mathrm{Cl}: 1.825-27.29, \mathrm{p}=0.005)$. ccc-DNA in liver tissue although higher in those with relapse $\left(4.19 \log _{10}\right.$ copies/ml (IQR: 3.5-6.99) than in those without relapse $3.2 \log _{10}$ copies/ml (IQR: 2.5 -5.1), was not statistically different between the 2 groups.

Treatment of children with relapse: Four (80\%) of the 5 children with biochemical relapse were treated with sequential therapy. The fifth child only had a transient biochemical relapse; hence, he was treated with antivirals alone. Of the 4 children who were treated with sequential therapy, 3 were HBeAg positive while 1 was $\mathrm{HBeAg}$ negative. None of the $3 \mathrm{HBeAg}$ positive children, showed $\mathrm{HBeAg}$ seroconversion at 1 year of therapy. Two of them achieved virological clearance (qHBV-DNA undetected). All 4 achieved normalization of their ALT levels at 1 year of therapy. The rest of the patients with only virological relapse are being continued on strict 3 monthly follow up for timely identification of biochemical relapse and possible re-treatment.

\section{Discussion:}

Virological relapse was seen in $38.7 \%$ and biochemical relapse in $16.1 \%$ of HBsAg reactive children whose antivirals were stopped as per the protocol. Most of the relapse occurred within a month of stopping the therapy. None of the HBsAg negative children developed relapse on follow up. HBeAg positive status at the time of stopping therapy (HR: 7.206, $p=0.005)$ and longer time taken for qHBV-DNA to become undetectable while on therapy (HR: 1.030, $p=0.037)$ were independent predictors of relapse. While $69.2 \%$ of HBeAg positive children developed virological relapse; only $16.7 \%$ of those with $\mathrm{HBeAg}$ negative status relapsed.

Most of the guidelines in adult hepatitis B recommend stopping antivirals after 12-36 months of $\mathrm{HBe}$ seroconversion with undetectable HBV-DNA and persistently normal ALT levels [4-6]. There are no pediatric studies to evaluate the timing and criteria for stopping antiviral therapy in children. Very low HBsAg seroconversion $(1.7-8.3 \%)$ and $\mathrm{HBeAg}$ seroconversion $(21-31.3 \%)$ rates observed in children on antivirals implies longer, often indefinite antiviral therapy [7-10]. Longer duration of therapy increases the cumulative risk of adverse events as well as risk of development of antiviral resistance [15]. Present study provides some insights into patient selection for stopping antivirals in children who fail to achieve HBsAg seroconversion. Virological relapse rate of $38.7 \%$ and biochemical relapse rate of $16.1 \%$ observed in children in our study is consistent with relapse rates observed in adults after antiviral discontinuation. The virological relapse rates reported have varied between $42 \%$ at 3 months to $68 \%$ at 6 years of follow 
up, while biochemical relapse rates have varied between $21.7 \%$ at 3 months to $63 \%$ at 6 years of follow up after antiviral discontinuation [16-17].

HBeAg positive status at the time of stopping therapy and longer time taken for qHBV-DNA to become undetectable were the predictors of relapse in the present study. The optimal end-point for stopping therapy would be the loss of HBsAg, often termed 'functional cure', but it is only rarely achievable in children [5,9-10]. Short of it, HBeAg seroconversion, coupled with HBV-DNA loss and ALT normalization characterizes a state of good immune control with low replicative phase of disease [5]. The high rates of relapse $(69.2 \%)$ in HBeAg positive children in the present study suggests that treatment withdrawal should not be attempted in absence of HBeAg seroconversion. The important predictors of relapse after stopping antivirals in adults include (i) higher qHBsAg level at the time of stopping the therapy [18-21]; (ii) shorter duration of consolidation therapy [19-20,22-24]; (iii) slower HBV-DNA decline while on therapy [25]; (iv) baseline pre-treatment HBV-DNA [26-27]; (v) hepatitis B core-related antigen (HBcrAg) [28-29]; and (vi) hepatitis B virus- ribonucleic acid (HBV-RNA [29]. The emphasis is maximum on qHBsAg levels at the time of stopping therapy and recently Asia Pacific Association for Study of Liver Diseases (APASL) has suggested qHBsAg less than $100 \mathrm{IU} / \mathrm{ml}$ as a safe endpoint for stopping long term antivirals [18]. $\mathrm{qHBsAg}$ levels was not significantly higher in the relapse in the present study. HBcrAg and HBV-RNA are among the newer serological markers predicting relapse either singly or in combination [28-29]. We evaluated the role of liver tissue ccc-DNA which although higher in relapse was not statistically different. This could be due to the smaller sample size and would need evaluation in larger multicentric studies. Recently, Lai et al investigated the effect of antiviral withdrawal in patients with undetectable ccc-DNA in the hepatocytes in adults [30]. All 13 patients with undetectable ccc-DNA randomized to stop therapy had virological relapse.

The main strength of our study is the pilot effort in determining the relapse rate and it's risk factors in children with CHB. The limitation is a smaller sample size due to single centre study and a short follow up of 12 months. However, we continue to closely follow-up these children. To conclude, the virological and biochemical relapse rates were $38.7 \%$ and $16.1 \%$ respectively with most relapses occurring within a month of stopping therapy. HBeAg positive status and longer duration to achieve virological remission while on therapy were independent predictors of relapse.

\section{Declarations:}

Conflict of interest: Piyush Upadhyay, Bikrant Bihari Lal, Vikrant Sood, Rajeev Khanna, Ekta Gupta, Archana Rastogi and Seema Alam have no potential conflict of interest to declare.

Ethical Approval: All procedures followed were in accordance with the ethical standards of the responsible committee on human experimentation (institutional and national) and with the Helsinki Declaration of 1975, as revised in 2008 (5). Informed consent was obtained from all patients for being included in the study. The study was approved by the Institutional Ethics Committee of Institute of Liver and Biliary Sciences, New Delhi, Indiavide letter no IEC 2019/67/MA 06. 
Consent to participate: Informed, written consent to participate was obtained from the parents of the children included in the study.

Funding: The authors did not receive support from any organization for the submitted work.

Author Contributions: All authors contributed to the study conception and design. Data collection was done by PU, BBL and VS. All the virological and serological studies were performed by EG. Histological evaluation and inputs were provided by AR. Analysis of the data and writing of the first draft of the manuscript was done by PU, SA and BBL. All authors commeneted on previous versions of manuscript, provided inputs and approved the final manuscript.

\section{References:}

1. Kim GA, Lim YS, Han S, et al. High risk of hepatocellular carcinoma and death in patients with immune-tolerant-phase chronic hepatitis B. Gut. 2018;67(5):945-952. doi:10.1136/gutjnl-2017314904

2. Lok AS. Hepatitis: Long-term therapy of chronic hepatitis B reverses cirrhosis. Nat Rev Gastroenterol Hepatol. 2013 Apr;10(4):199-200. doi: 10.1038/nrgastro.2013.13. Epub 2013 Jan 29. PMID: 23358397.

3. WHO Guidelines for the prevention, care and treatment of persons with chronic hepatitis B infection 2015 Mar. ISBN-13: 978-92-4-154905-9.

4. Sarin SK, Kumar M, Lau GK, Abbas Z, Chan HL, Chen CJ, Chen DS, Chen HL, Chen PJ, Chien RN, et al. Asian-Pacific clinical practice guidelines on the management of hepatitis B: a 2015 update. Hepatol Int. 2016;10:1-98

5. European Association for the Study of the Liver. Electronic address: easloffice@easloffice.eu.; European Association for the Study of the Liver. EASL 2017 Clinical Practice Guidelines on the management of hepatitis B virus infection. J Hepatol. 2017;67:370-398.

6. Terrault NA, Bzowej NH, Chang KM, Hwang JP, Jonas MM, Murad MH; American Association for the Study of Liver Diseases. AASLD guidelines for treatment of chronic hepatitis B. Hepatology. 2016 Jan;63(1):261-83. doi: 10.1002/hep.28156. Epub 2015 Nov 13. PMID: 26566064; PMCID: PMC5987259.

7. Jonas MM, Chang MH, Sokal E, Schwarz KB, Kelly D, Kim KM, Ling SC, Rosenthal P, Oraseanu D, Reynolds L, Thiry A, Ackerman P. Randomized, controlled trial of entecavir versus placebo in children with hepatitis B envelope antigen-positive chronic hepatitis B. Hepatology. 2016 Feb; 63(2):377-87.

8. Murray KF, Szenborn L, Wysocki J, et al. Randomized, placebo-controlled trial of tenofovir disoproxil fumarate in adolescents with chronic hepatitis B. Hepatology. 2012;56(6):2018-2026.

doi:10.1002/hep.25818

9. Jonas MM, Lok AS, McMahon BJ, et al. Antiviral therapy in management of chronic hepatitis B viral infection in children: A systematic review and meta-analysis. Hepatology. 2016;63(1):307-318. 
doi:10.1002/hep.28278

10. Lal, B.B., Sood, V., Khanna, R. et al. Pegylated interferon-based sequential therapy for treatment of $\mathrm{HBeAg}$ reactive pediatric chronic hepatitis B-First study in children. Indian J Gastroenterol <background-color:\#FFCC66;bvertical-align:super;>37</background-color:\#FFCC66;bverticalalign:super;><bvertical-align:super;>,</bvertical-align:super;><bvertical-align:super;> </bverticalalign:super;>326-334 (2018)

11. Schwimmer JB, Dunn W, Norman GJ, Pardee PE, Middleton MS, Kerkar N, Sirlin CB. SAFETY study: alanine aminotransferase cutoff values are set too high for reliable detection of pediatric chronic liver disease. Gastroenterology. 2010 Apr;138(4):1357-64, 1364.e1-2. doi:

10.1053/j.gastro.2009.12.052. Epub 2010 Jan 11.

12. Ishak K, Baptista A, Bianchi L, et al. Histological grading and staging of chronic hepatitis. J Hepatol. 1995;22(6):696-699. doi:10.1016/0168-8278(95)80226-6

13. Takkenberg RB, Zaaijer HL, Molenkamp R, Menting S, Terpstra V, Weegink CJ, Dijkgraaf MG, Jansen PL, Reesink HW, Beld MG. Validation of a sensitive and specific real-time PCR for detection and quantitation of hepatitis B virus covalently closed circular DNA in plasma of chronic hepatitis B patients. J Med Virol. 2009 Jun;81(6):988-95.

14. Gupta E, Kumar A, Choudhary A, Kumar M, Sarin SK. Serum hepatitis B surface antigen levels correlate with high serum HBV DNA levels in patients with chronic hepatitis $\mathrm{B}$ : a cross-sectional study. Indian J Med Microbiol. 2012 Apr-Jun;30(2):150-4. doi: 10.4103/0255-0857.96664. PMID: 22664428.

15. Sokal EM, Paganelli M, Wirth S, et al. Management of chronic hepatitis B in childhood: ESPGHAN clinical practice guidelines: consensus of an expert panel on behalf of the European Society of Pediatric Gastroenterology, Hepatology and Nutrition. J Hepatol. 2013;59(4):814-829. doi:10.1016/j.jhep.2013.05.016

16. Chen $\mathrm{CH}$, Lu SN, Hung $\mathrm{CH}$, Wang JH, Hu TH, Changchien CS, Lee CM. The role of hepatitis B surface antigen quantification in predicting HBsAg loss and HBV relapse after discontinuation of lamivudine treatment. J Hepatol. 2014;61:515-522.

17. Kaewdech A, Tangkijvanich P, Sripongpun P, Witeerungrot T, Jandee S, Tanaka Y, Piratvisuth T. Hepatitis B surface antigen, core-related antigen and HBV RNA: Predicting clinical relapse after NA therapy discontinuation. Liver Int. 2020 Dec;40(12):2961-2971.

18. Kao JH, Jeng WJ, Ning Q, et al. APASL guidance on stopping nucleos(t)ide analogues in chronic hepatitis B patients. Hepatol Int. 2021;15(4):833-851. doi:10.1007/s12072-021-10223-5

19. Song DS, Jang JW, Yoo SH, et al. Improving the Prediction of Relapse After Nucleos(t)ide Analogue Discontinuation in Patients With Chronic Hepatitis B. Clin Infect Dis. 2021;73(4):e892-e903. doi:10.1093/cid/ciab007

20. Liu Y, Jia M, Wu S, Jiang W, Feng Y. Predictors of relapse after cessation of nucleos(t)ide analog treatment in HBeAg-negative chronic hepatitis B patients: A meta-analysis. Int J Infect Dis. 2019;86:201-207. doi:10.1016/j.ijid.2019.07.036 
21. Tout I, Lampertico P, Berg T, Asselah T. Perspectives on stopping nucleos(t)ide analogues therapy in patients with chronic hepatitis B. Antiviral Res. 2021;185:104992.

doi:10.1016/j.antiviral.2020.104992

22. Chi $H$, Hansen $B E$, Yim $C$, et al. Reduced risk of relapse after long-term nucleos(t)ide analogue consolidation therapy for chronic hepatitis B. Aliment Pharmacol Ther. 2015;41(9):867-876. doi:10.1111/apt.13150

23. Jeng WJ, Sheen IS, Chen YC, et al. Off-therapy durability of response to entecavir therapy in hepatitis B e antigen-negative chronic hepatitis B patients. Hepatology. 2013;58(6):1888-1896. doi:10.1002/hep.26549

24. Papatheodoridis G, Vlachogiannakos I, Cholongitas E, Wursthorn K, Thomadakis C, Touloumi G, Petersen J. Discontinuation of oral antivirals in chronic hepatitis B: A systematic review. Hepatology.2016;63:1481-1492.

25. Jeng WJ, Chen YC, Chien RN, Sheen IS, Liaw YF. Incidence and predictors of hepatitis B surface antigen seroclearance after cessation of nucleos(t)ide analogue therapy in hepatitis $B$ e antigennegative chronic hepatitis B. Hepatology. 2018;68(2):425-434. doi:10.1002/hep.29640

26. Kuo MT, Hu TH, Hung $\mathrm{CH}$, et al. Hepatitis $B$ virus relapse rates in chronic hepatitis $B$ patients who discontinue either entecavir or tenofovir. Aliment Pharmacol Ther. 2019;49(2):218-228. doi:10.1111/apt.15053

27. Tseng TN, Hu TH, Wang JH, et al. Incidence and Factors Associated With HBV Relapse After Cessation of Entecavir or Tenofovir in Patients With HBsAg Below $100 \mathrm{IU} / \mathrm{mL}$. Clin Gastroenterol Hepatol. 2020;18(12):2803-2812.e2. doi:10.1016/j.cgh.2020.04.037

28. Liao G, Ding X, Xia M, et al. Hepatitis B Core-Related Antigen is a Biomarker for off-Treatment Relapse After Long-Term Nucleos(t)ide Analog Therapy in Patients with Chronic Hepatitis B. Int J Gen Med. 2021;14:4967-4976. Published 2021 Aug 28. doi:10.2147/IJGM.S321253

29. Fan R, Peng J, Xie Q, et al. Combining Hepatitis B Virus RNA and Hepatitis B Core-Related Antigen: Guidance for Safely Stopping Nucleos(t)ide Analogues in Hepatitis B e Antigen-Positive Patients With Chronic Hepatitis B. J Infect Dis. 2020;222(4):611-618. doi:10.1093/infdis/jiaa136

30. Lai CL, Wong DK, Wong GT, Seto WK, Fung J, Yuen MF. Rebound of HBV DNA after cessation of nucleos/tide analogues in chronic hepatitis B patients with undetectable covalently closed. JHEP Rep. 2020;2(3):100112. Published 2020 Mar 29. doi:10.1016/j.jhepr.2020.100112

\section{Tables:}

Table 1: Baseline clinical and laboratory profile of the $31 \mathrm{HBsAg}$ positive at the time of stopping antiviral treatment 


\section{Parameter}

Age [median (IQR)]

15 years $(11.5-17)$

Gender

Male

$30(96.8 \%)$

Female

$1(3.2 \%)$

HBeAg status at the time of enrolment

Reactive

$13(41.9 \%)$

Non reactive

$18(58.1 \%)$

ALT at the time of enrolment

$30 \mathrm{IU} / \mathrm{L}(23-35)$

Liver histology findings

Histological activity index

$0-1$

$20(64.5 \%)$

2-3

$11(35.5 \%)$

$>3$

0

Fibrosis

0

$14(45.2 \%)$

1

$13(41.9 \%)$

2

$4(12.9 \%)$

$>2$

0

ccc-DNA ( $\log _{10}$ in copies/ml) [median(IQR)]

$4(3.1-5.4)$

Liver stiffness by transient elastography

$5 \mathrm{kPa}(4.4-5.4)$

Genotype $(n=24)$

Genotype D

$18(75 \%)$

Genotype A

$4(16.7 \%)$

Genotype C

$2(8.3 \%)$

Duration of antiviral therapy [median(IQR)]

60 months (36-78)

Previous sequential therapy with peg-IFN

$13(41.9 \%)$

Duration of antiviral treatment post sequential therapy [median(IQR)]

36 months (27-54)

Time taken for qHBV-DNA to become undetected during antiviral therapy [median(IQR)]

32 months (16-49) 
*Effect size described as odds ratio, \#Effect size described as mean difference

Abbreviations: ALT: Alanine aminotransferase; HBeAg: Hepatitis B e antigen; HBsAg: Hepatitis B surface antigen; IQR: Inter Quartile Range; qHBV-DNA: Quantitative HBV-DNA; Peg-IFN: Pegylated interferon

Table 2: Cox univariate and regression analyses of risk factors for development of virological relapse after stopping antiviral treatment in children with chronic hepatitis $B$ 


\section{Univariate Analysis}

\begin{tabular}{|c|c|c|c|c|}
\hline Variable & $\begin{array}{l}\text { Relapse } \\
(n=12)\end{array}$ & $\begin{array}{l}\text { No Relapse } \\
(n=19)\end{array}$ & $\begin{array}{l}\text { Hazard } \\
\text { ratio } \\
(95 \% \mathrm{Cl})\end{array}$ & Value \\
\hline $\begin{array}{l}\text { Age at enrolment (years) [median } \\
(\mathrm{IQR}) \text { ] }\end{array}$ & $16(13.5-17)$ & $13(10-17)$ & $\begin{array}{l}1.129 \\
(0.96- \\
1.326)\end{array}$ & 0.140 \\
\hline $\begin{array}{l}\text { qHBsAg }\left(\log _{10}\right) \\
\text { [median (IQR)] }\end{array}$ & $3.84(3.15-4.41)$ & $\begin{array}{l}3.71(2.92- \\
4.19)\end{array}$ & $\begin{array}{l}1.465 \\
(0.806- \\
2.66)\end{array}$ & 0.211 \\
\hline $\begin{array}{l}\text { HBeAg positive status } \\
\text { n (\%) }\end{array}$ & $9(75 \%)$ & $4(21 \%)$ & $\begin{array}{l}7.058 \\
(1.825- \\
27.29)\end{array}$ & 0.005 \\
\hline $\begin{array}{l}\text { Duration of antiviral treatment } \\
\text { (months) } \\
\text { [median (IQR)] }\end{array}$ & $60(36-78)$ & 48 (32-72) & $\begin{array}{l}0.960 \\
(0.905- \\
1.019)\end{array}$ & 0.136 \\
\hline $\begin{array}{l}\text { History of sequential treatment, } \mathrm{n} \\
(\%)\end{array}$ & 5 (41.6) & $8(42.1)$ & $\begin{array}{l}0.982 \\
(0.227- \\
4.251)\end{array}$ & 1.000 \\
\hline $\begin{array}{l}\text { Duration of normal ALT on } \\
\text { antivirals (months) } \\
\text { [median (IQR)] }\end{array}$ & $16(13.5-33)$ & $32(19.5-48)$ & $\begin{array}{l}0.979 \\
(0.932- \\
1.029)\end{array}$ & 0.07 \\
\hline $\begin{array}{l}\text { Time taken for qHBV-DNA to } \\
\text { become undetectable (months), } \\
\text { [median (IQR)] }\end{array}$ & $46(23-64)$ & $24(11-39)$ & $\begin{array}{l}1.024 \\
(1.003- \\
1.046)\end{array}$ & 0.028 \\
\hline $\begin{array}{l}\text { Duration since HBeAg } \\
\text { seroconversion (months) } \\
\text { [median (IQR)] }\end{array}$ & $24(12-28)$ & $24(12-36)$ & $\begin{array}{l}1.103 \\
(0.417- \\
2.919)\end{array}$ & 0.843 \\
\hline $\begin{array}{l}\text { ccc-DNA in liver }\left(\log _{10}\right) \text { copies } / \mathrm{ml} \text {, } \\
\text { [median (IQR)] }\end{array}$ & $4.19(3.5-6.99)$ & $3.2(2.5-5.1)$ & $\begin{array}{l}1.176 \\
(0.893- \\
1.550)\end{array}$ & 0.248 \\
\hline
\end{tabular}

Cox Regression Analysis 
Lower Upper

HBeAg positive status

Time taken for qHBV-DNA to become undetected (months) $\begin{array}{lll}1.975 & 7.829 & 0.005\end{array}$

0.029

4.356

0.037
1.807

28.743

$\begin{array}{lll}1.030 & 1.002 & 1.058\end{array}$

Abbreviations: ALT:Alanine aminotransferase; Cl: Confidence interval; Exp (B): Exponential B; IQR : Inter Quartile Range; HBeAg: Hepatitis B e antigen; qHBsAg: Quantitative HBsAg; qHBV-DNA:

Quantitative Hepatitis B virus deoxyribonucleic acid; ccc DNA: Circular covalently closed circular deoxyribonucleic acid;

\section{Figures}

Pediatric Chronic Hepatitis B( HBeAg + ve \& HBeAg -ve)

$\checkmark$ On antivirals for $>24$ months

$\checkmark$ ALT levels Persistently $<1.5$ ULN

$\checkmark$ Persistently qHBV DNA undetected

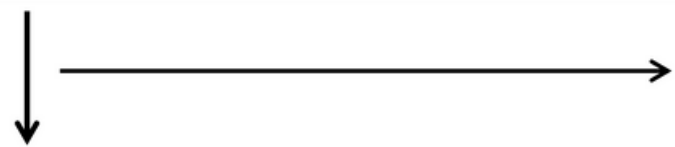

Assessment for treatment discontinuation: Liver Biopsy (HAI, Fibrosis)

Quantitative cccDNA estimation in the liver

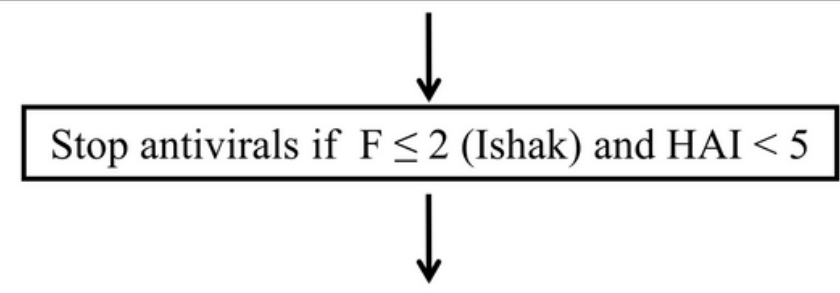

Follow up at 1 month, 3 months, then 3 monthly:

ALT, HBV DNA, HBeAg, AFP and USG abdomen

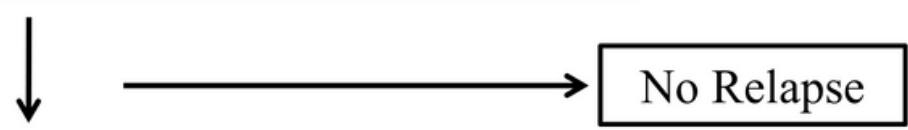

Virological Relapse: qHBV DNA > $2000 \mathrm{IU} / \mathrm{ml}$

Biochemical Relapse: ALT $>2$ times ULN

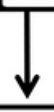

Biochemical Relapse : NA + Peg IFN alpha 2b (60 $\mu \mathrm{g} / \mathrm{m}^{2} /$ week) subcutaneously for 48 weeks
Exclusion:

- With family h/o Cirrhosis \&HCC

- Decompensation

- HCC

Figure 1

Study Design 
Abbreviations:AFP: alfa-fetoprotein; ALT: Alanine aminotransferase; HBeAg: Hepatitis B e antigen; HBVDNA: Hepatitis B virus deoxyribonucleic acid; HCC: Hepatocellular carcinoma; ccc-DNA: Circular covalently closed DNA; F: Fibrosis; HAl: Histological activity index; NA: Nucleos(t)ide analogue; Peg-IFN: Pegylated interferon; qHBV-DNA: Quantitative HBV DNA; ULN: Upper Limit of Normal; USG: Ultrasonogram
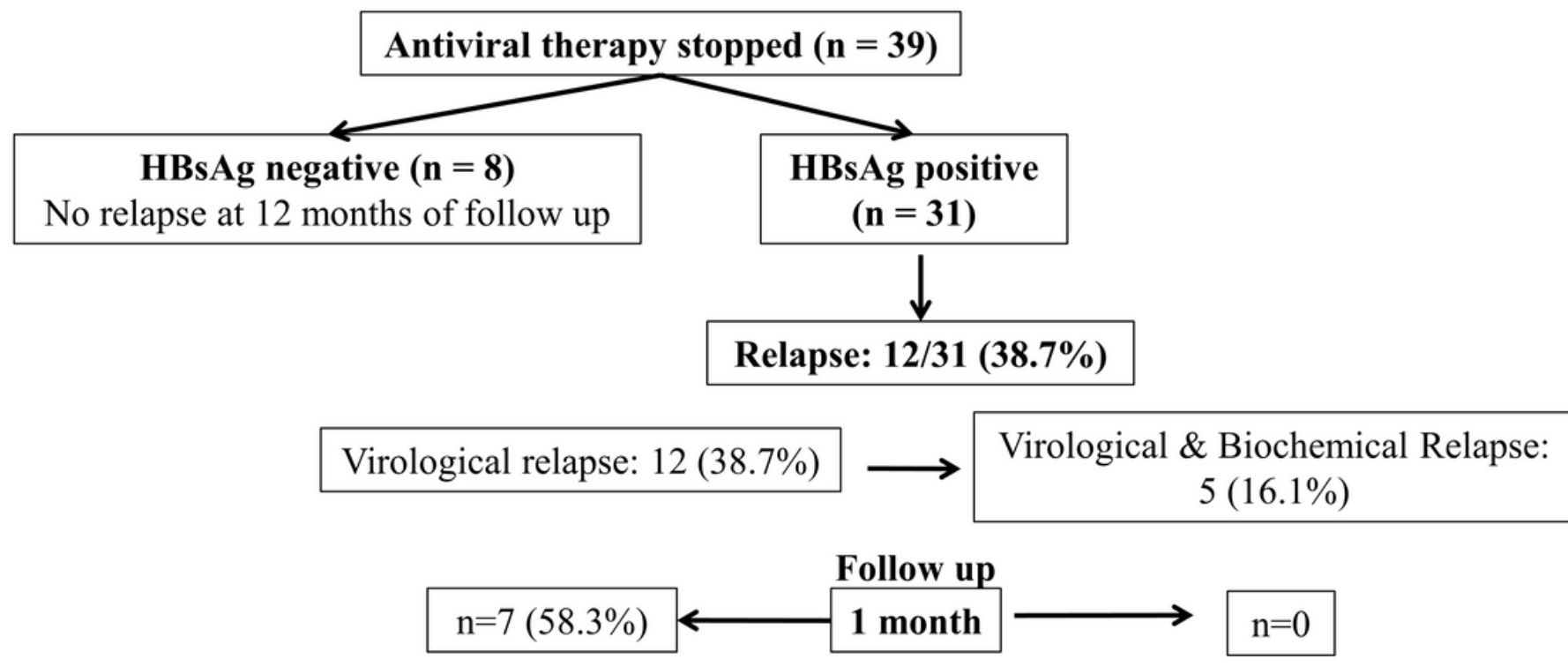

\begin{tabular}{|l|c|c|}
\hline \multicolumn{3}{|c|}{$\begin{array}{c}\text { Patients with } \\
\text { virological \& } \\
\text { biochemical relapse }\end{array}$} \\
\hline & \multicolumn{2}{|c|}{ Time of relapse } \\
\hline $\begin{array}{l}\text { Pati } \\
\text { ent }\end{array}$ & $\begin{array}{c}\text { Virologi } \\
\text { cal }\end{array}$ & $\begin{array}{c}\text { Bioche } \\
\text { mical }\end{array}$ \\
\hline 1 & 1 & 6 \\
\hline 2 & 3 & 3 \\
\hline 3 & 3 & 3 \\
\hline 4 & 6 & 6 \\
\hline 5 & 9 & 9 \\
\hline
\end{tabular}

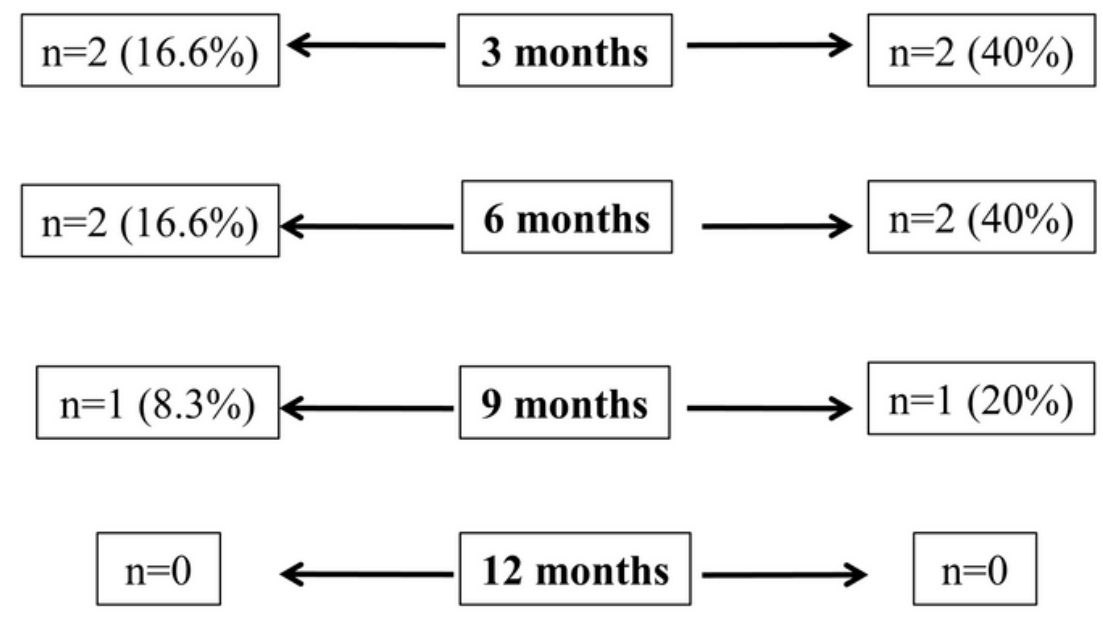

Figure 2

Pattern of relapse after stopping antiviral therapy in children with chronic hepatitis B Abbreviations: HBeAg: Hepatitis B e antigen; HBsAg: Hepatitis B surface antigen 


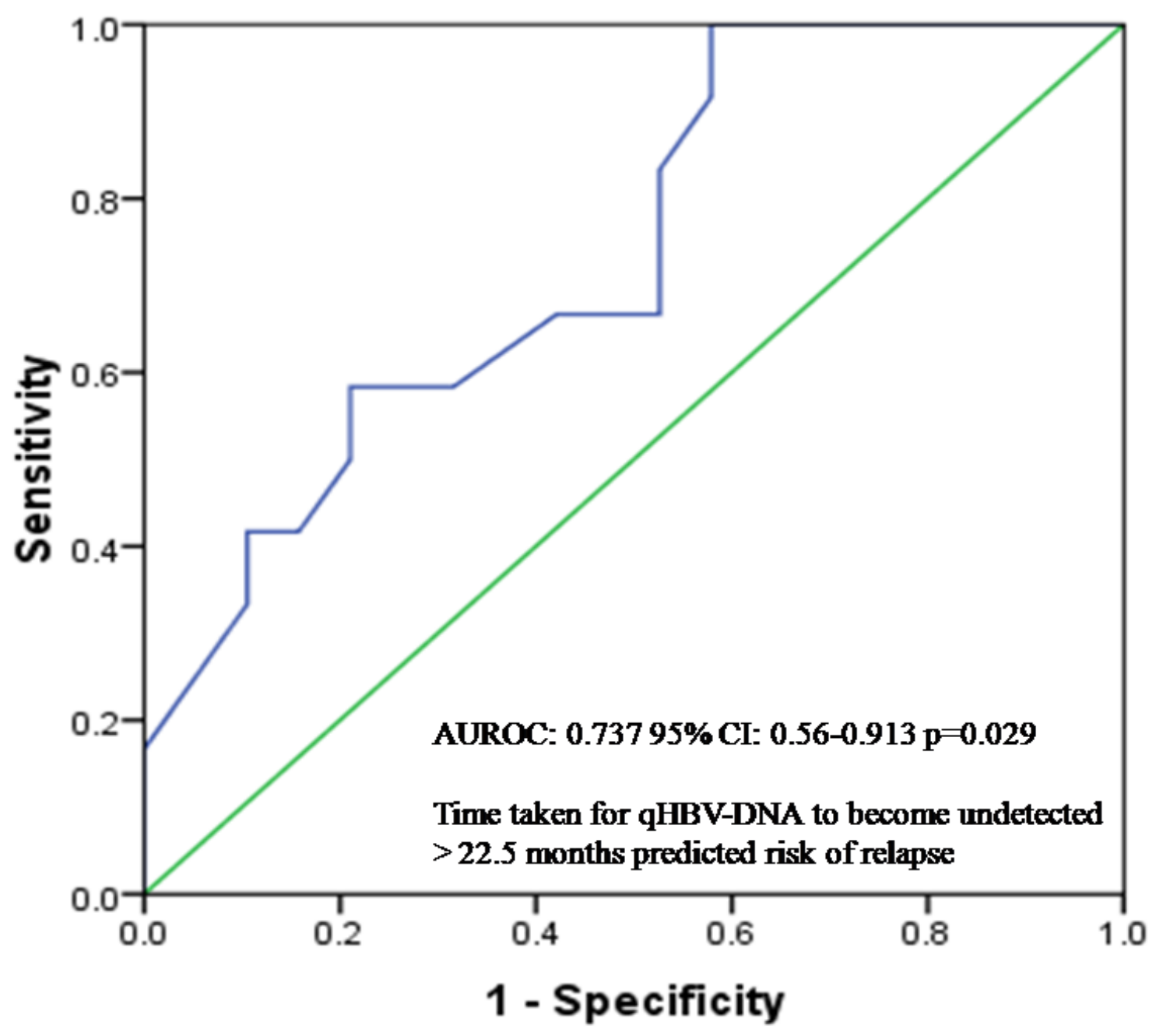

Figure 3

Receiver operating characteristic curve showing the effect of time taken for qHBV-DNA to become undetectable in predicting relapse after stopping antiviral treatment in children with chronic hepatitis $B$ Abbreviations: AUROC: Area under receiver operating characteristic curve; Cl: Confidence interval; qHBVDNA: Quantitative HBV DNA 


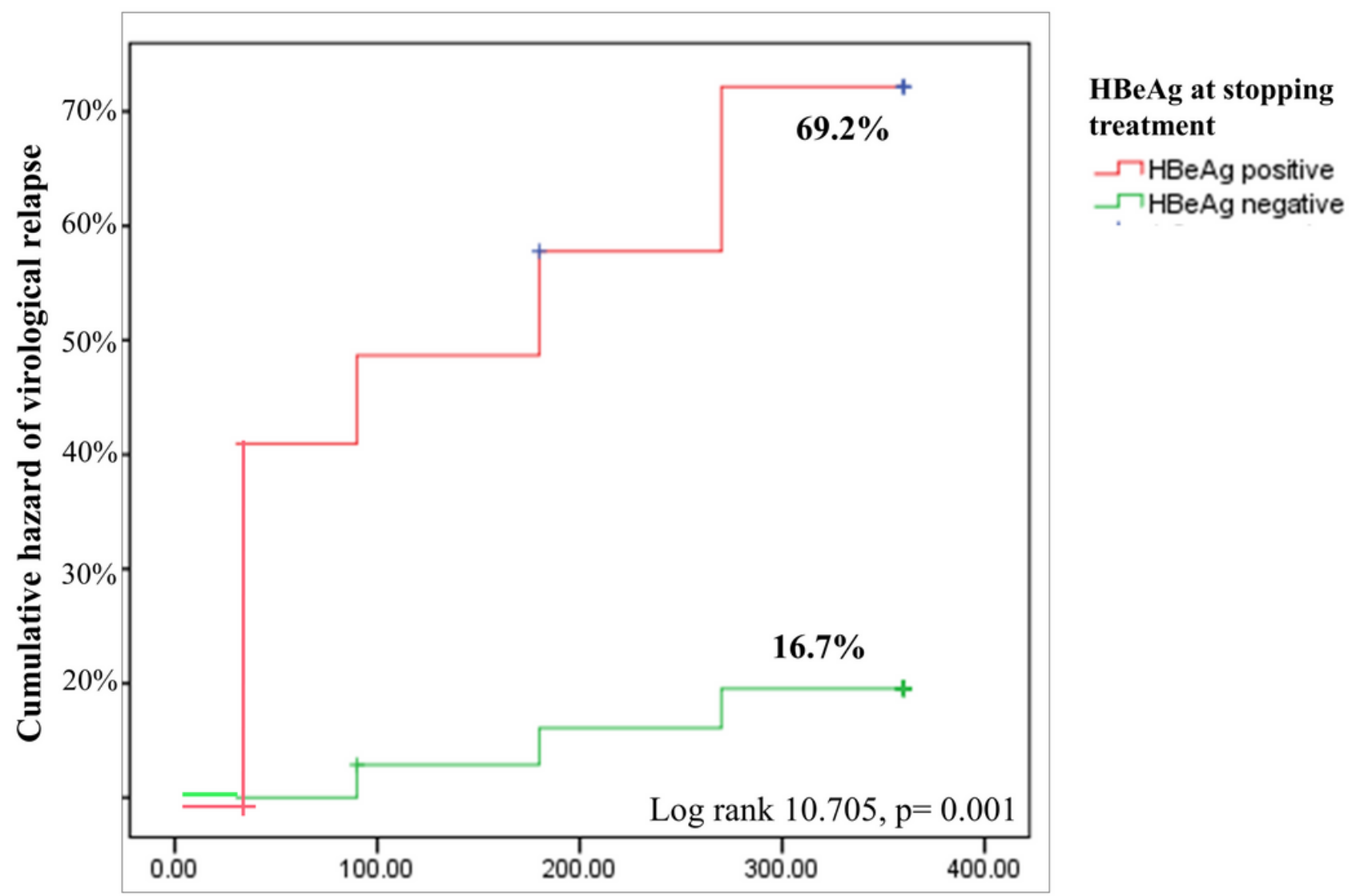

Time (days) after stopping anti-virals

Figure 4

Difference in relapse rate between children who were HBeAg positive or negative at the time of stopping antiviral treatment

Abbreviations: HBeAg: Hepatitis B e antigen 